\title{
ELECTRON DONORS AND CYANOIMIDAZOLE ACCEPTORS: CYCLIC VOLTAMMETRY AND MOLECULAR ORBITAL STUDY
}

\author{
DAVID S. ALLAN, DEBORA F. BERGSTROM and PAUL G. RASMUSSEN* \\ Department of Chemistry and Macromolecular Science and Engineering Program, \\ The University of Michigan, Ann Arbor, MI 48109 (U.S.A.)
}

(Received January 28, 1988; accepted February 10, 1988)

\begin{abstract}
Voltammetric measurements on a series of cyanoimidazoles and their metal complexes are reported and compared with those for various donors and acceptors measured under the same conditions. LUMO energies from extended Hückel calculations correlate well with reduction potentials of cyanoimidazoles. Extended Hückel calculations also give insights into the interaction of the metal complexes of tetracyanobiimidazole and the nature of molecular stacking.
\end{abstract}

\section{Introduction}

Our interest in cyanoimidazoles and their metal complexes arises from our studies of new materials with interesting electron transport properties. Cyanoimidazoles as a class are well suited for development as electron acceptors or as $\pi$-accepting ligands in metal complex acceptors.

A number of structural features have been identified as prerequisites for conductive charge-transfer salts [1 - 7]. Such materials should be planar to allow them to stack closely in the crystalline state. They should possess an extended $\pi$-system, and the charge on the molecules should be distributed to the periphery of the molecule to delocalize charge and minimize Coulombic repulsions [2]. Furthermore, the electron donor and electron acceptor components should be matched closely in oxidation and reduction potentials to allow for partial charge transfer [6].

Cyanoimidazoles fulfill these requirements and possess several other advantages. 4,5-Dicyanoimidazole (1) and 4,4',5,5'-tetracyano-2,2'-biimidazole $\left(\mathrm{H}_{2} \mathrm{TcBiim}\right)(2)$ are quite planar both as neutral molecules and in complexes $[8,9]$. The $\pi$-systems of these molecules extend over all non-hydrogen atoms, and negative charge is delocalized into the nitrile groups at the periphery of the molecule. The importance of the nitrile groups in determining

*Author to whom correspondence should be addressed. 
<smiles>N#Cc1nc[nH]c1C#N</smiles>

1<smiles>N#Cc1nc(-c2nc(C#N)c(C#N)[nH]2)[nH]c1C#N</smiles>

2

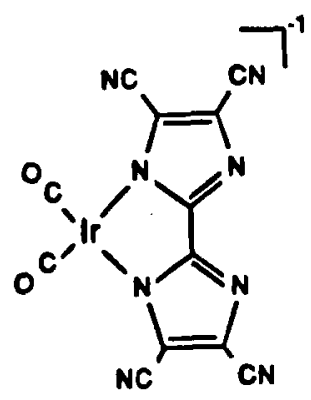

3

the electronic character of these molecules is demonstrated by their high acidity $\left(\mathrm{p} K_{\mathrm{a}}(1)=5.0 ; \mathrm{p} K_{\mathrm{a} 1}(2)=2.1 ; \mathrm{p} K_{\mathrm{a} 2}(2)=5.5 ; \mathrm{p} K_{\mathrm{a}}(\right.$ imidazole $\left.)=14.5\right)$ [10] and their ability to stabilize metals in low oxidation states through backbonding (3) [11]. Finally, cyanoimidazoles can be further functionalized, providing opportunities for modification of chemical or electronic properties.

To date, the number of good 'partial charge-transfer' conductors remains small [3]. In order to design such materials rationally, a knowledge of the electrochemical behavior of potentially matching donors and acceptors is indispensable $[2,3,4]$. Therefore, we have measured the cyclic voltammograms of a number of donors and acceptors based on cyanoimidazoles and their metal complexes. Although the metal complexes are prepared in the reduced state, their role is that of an acceptor. This is akin to the use of $\mathrm{TCNQ}^{-1}$ in the synthesis of well-known charge transfer complexes. In fact, we have described the corresponding neutral Ir(II) species elsewhere [12].

In order to avoid the difficulties inherent in comparing electrochemical data measured under different experimental conditions, the cyclic voltammograms of some common donors and acceptors were recorded under conditions identical to our measurements on the cyanoimidazoles.

We have also performed extended Hückel calculations on a number of organic acceptors. Correlation of calculated energies for lowest unoccupied molecular orbitals (LUMOs) with measured reduction potentials provides a computational tool for assessing proposed acceptors prior to their synthesis in the laboratory. Calculations on metal complexes of tetracyanobiimidazole provide information on their preferred geometry and the nature of the interaction between these complexes.

Results and discussion

Cyclic voltammetric measurements were made on a number of derivatives of 4,5-dicyanoimidazole. The results are summarized in Table 1 , along with potentials gleaned from the literature for some compounds of 
TABLE 1

Electrochemical data for cyano-based acceptors

\begin{tabular}{llll}
\hline Compound & $\begin{array}{l}E_{\text {red }}{ }^{\mathrm{a}} \\
(\mathrm{V})\end{array}$ & Reversibility $^{\mathrm{b}}$ & Ref. \\
\hline TCNQ & -0.25 & $*$ & $\mathrm{c}$ \\
TCNE & -0.29 & $*$ & $\mathrm{c}$ \\
Pyromellitonitrile & -0.92 & & $\mathrm{~d}$ \\
$N$-methyltricyanoimidazole & -1.83 & $\dagger$ & $\mathrm{c}$ \\
4-Cyanopyridine & -1.93 & & $\mathrm{~d}$ \\
Phthalonitrile & -2.02 & $*$ & $\mathrm{c}$ \\
$\begin{array}{l}\text { Dimethyltetracyano- } \\
\text { biimidazole }\end{array}$ & -2.05 & + & $\mathrm{c}$ \\
$N$-vinyldicyanoimidazole & -2.06 & + & $\mathrm{c}$ \\
Isophthalonitrile & -2.07 & & $\mathrm{c}$ \\
$N$-methyl-2-bromodicyano- & -2.31 & + & $\mathrm{c}$ \\
imidazole & & & $\mathrm{d}$ \\
$N$-methyldicyanoimidazole & -2.36 & $*$ & $\mathrm{~d}$ \\
Benzonitrile & -2.64 & & $\mathrm{~d}$ \\
4-Tolunitrile & -2.65 & & \\
4 -Cyanoaniline & -3.02 & & \\
\hline
\end{tabular}

${ }^{\text {a }}$ Measured in $\mathrm{CH}_{3} \mathrm{CN}$ us. $\mathrm{Ag} / \mathrm{Ag}^{+}$.

b*, Quasi-reversible, ${ }^{\dagger}$, irreversible.

c This work.

dRefs. 13, 14 .

interest. The literature values have been adjusted to the scale of the present work by duplicating measurements under our conditions for a subgroup of the compounds.

The reduction potentials measured for tetracyanoquinodimethane (TCNQ) and tetracyanoethylene (TCNE) were close to those reported in the literature $[13-15]$. The cyanoimidazoles are significantly harder to reduce than TCNQ and TCNE; however, they are more easily reduced than the other nitrile-containing compounds measured.

Of the cyanoimidazoles studied (see Fig. 1), only the prototypical compound, 4,5-dicyano-1-methylimidazole, yielded a nearly reversible waveform. The 1-vinyl derivative gave a reduction wave, but a very small re-oxidation wave. This result suggests that the vinyl derivative may react chemically after reduction, perhaps polymerizing on the electrode. Attempts at chemically initiated anionic polymerization of this molecule have been unsuccessful, however.

The 2,4,5-tricyano-1-methylimidazole and 4,4',5,5'-tetracyano-1,1'dimethyl-2,2'-biimidazole derivatives both exhibited somewhat different behavior. The waveforms have two peaks in the reducing scan and no reoxidation in the return scan, suggesting two one-electron reductions followed by irreversible chemical reaction. Changing the working electrode to glassy carbon did not significantly alter the appearance of the waveforms or 

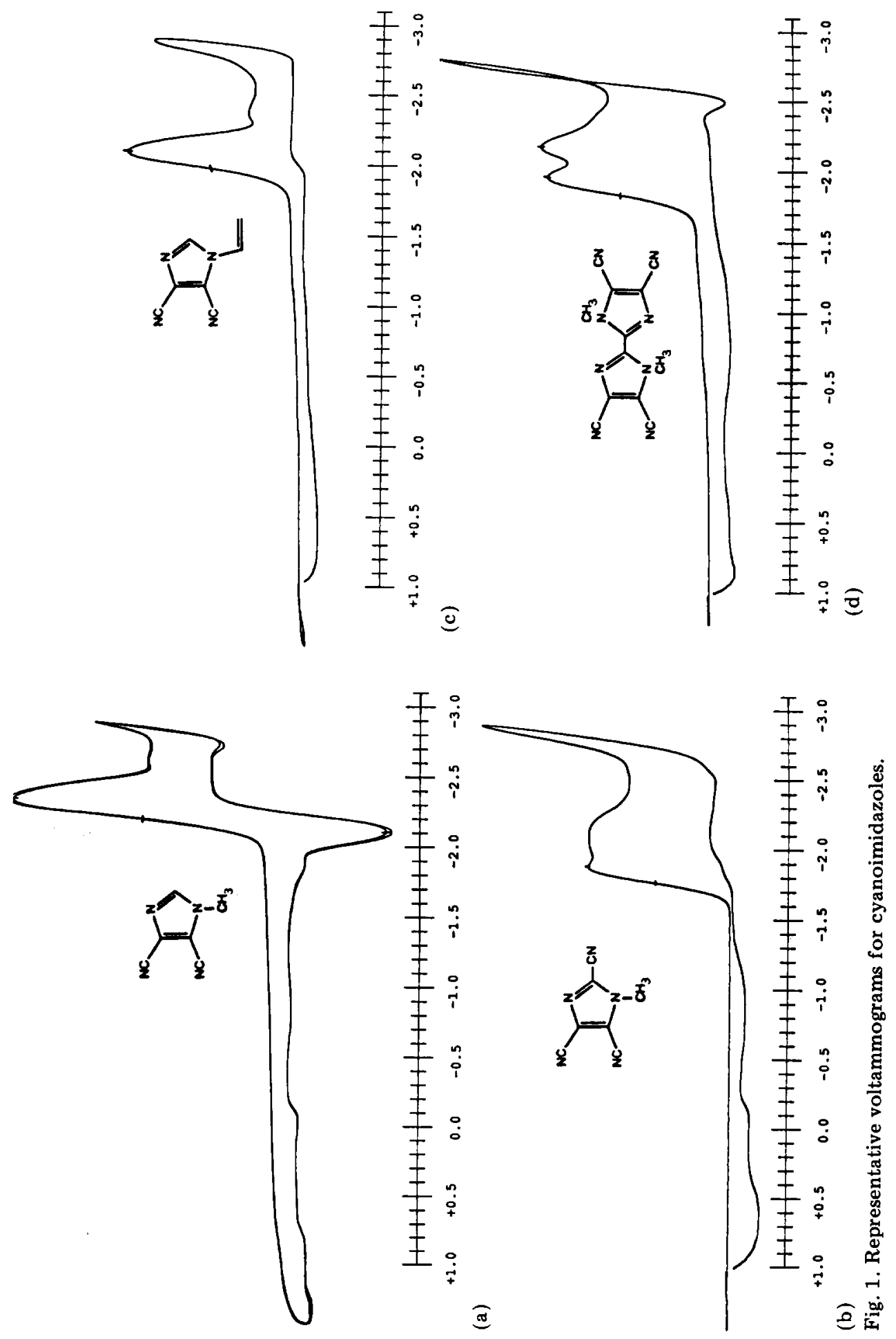
the observed potentials, nor did sweeping the potential at a faster rate. The cyclic voltammetric results can be combined with the results of molecular orbital calculations to yield new insights into the behavior and design of acceptors based on cyanoimidazoles.

Extended Hückel molecular orbital calculations were carried out on a number of derivatives of 4,5-dicyanoimidazole and some well-known cyanobased $\pi$-acceptors. Some of the results of these calculations are summarized in Table 2.

\section{TABLE 2}

Results of extended Hückel calculations on cyano-based acceptors

\begin{tabular}{llc}
\hline Compound & HOMO $(\mathrm{eV})$ & LUMO $(\mathrm{eV})$ \\
\hline TCNQ & -12.17 & -10.83 \\
TCNE & -13.11 & -10.57 \\
Pyromellitonitrile & -12.58 & -9.98 \\
4-Cyanopyridine & -12.23 & -9.72 \\
Phthalonitrile & -12.69 & -9.65 \\
$N$-vinyldicyanoimidazole & -12.20 & -9.47 \\
$N$-methyltricyanoimidazole & -12.29 & -9.45 \\
Dimethyltetracyanobiimidazole & -11.92 & -9.44 \\
$N$-methyldicyanoimidazole & -12.25 & -9.43 \\
Benzonitrile & -12.73 & -9.31 \\
4-Cyanoaniline & -12.02 & -8.92 \\
\hline
\end{tabular}

The lowest unoccupied molecular orbital (LUMO) energies for cyanoimidazole derivatives are all clustered around the same value, about -9.45 eV. LUMO energies for the best acceptors, such as TCNQ and TCNE, are significantly more negative than those of cyanoimidazoles, while LUMO energies for other cyanoaromatics examined are somewhat less negative. Thus, cyanoimidazoles are predicted to have acceptor power intermediate between the two extremes represented. The correlation between acceptor power and LUMO level is further demonstrated in Fig. 2.

Given the diversity of molecular types represented in the plot, the correlation seems somewhat surprising, but may be quite useful for predicting electron-accepting ability from molecular orbital calculations. The electron-accepting ability of hitherto unsynthesized members of the cyanoimidazole family may be estimated from this correlation, provided that they do not differ greatly in geometry or functionality from the compounds already tabulated.

The electron-accepting power of cyanoimidazoles, along with their chelating geometry as biimidazoles, makes them good $\pi$-acid ligands. These ligands serve to stabilize low-valent metals. The resulting metal complexes tend to oligomerize in solution and can be partially oxidized to form organometallic conductors [16]. 


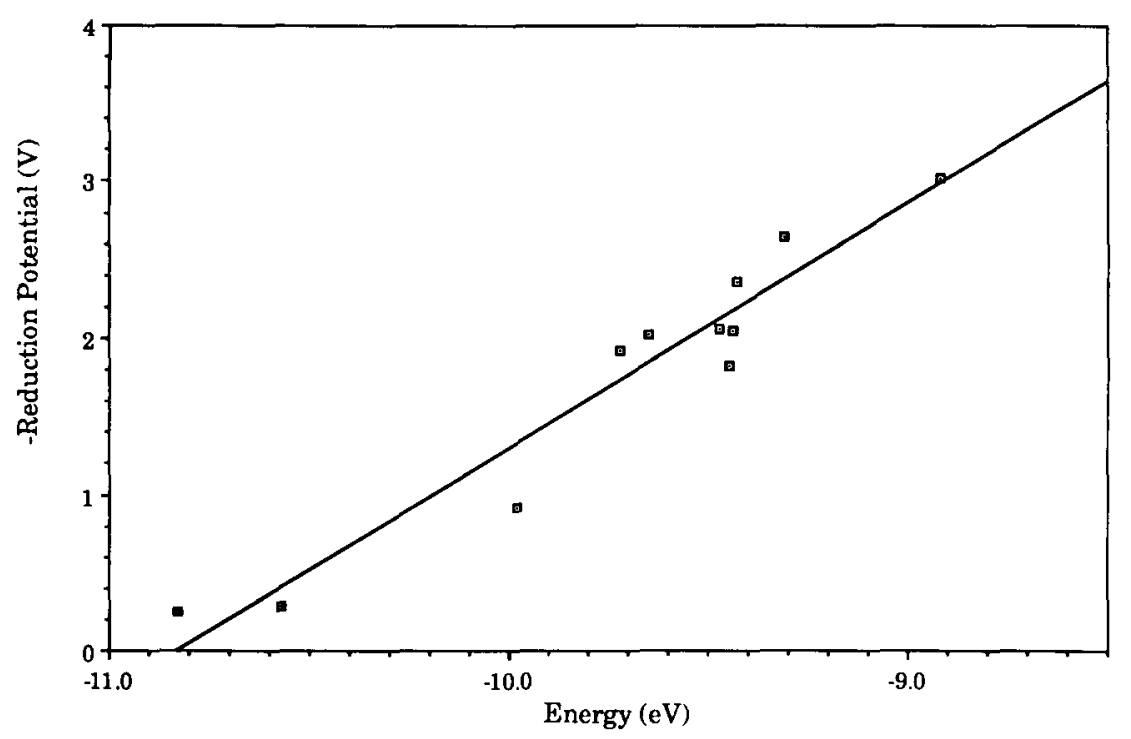

Fig. 2. Correlation of acceptor LUMO with reduction potential.

In an effort to synthesize new linear chain metal compounds, we have done experiments on a family of compounds using the flat delocalized iridium(I) complex anion (3) with the ligand tetracyanobiimidazole [16]. This anion has been electrochemically oxidized under a variety of experimental conditions to form conducting solids [17]. In early work, electrolyte salts of tetrahedral symmetry such as tetraalkylammonium perchlorates and tetrafluoroborates were used. These ions are incorporated into the solid products to provide charge balance. Since in these solids the metal complexes have a negative $2 / 3$ charge per stacking unit, the resulting compounds require fractional stoichiometries of these ions to achieve neutrality.

Another possibility is to make use of tetrathiofulvalene and related compounds as counterions in the synthesis of these iridium complexes. Unlike the alkylammonium cations, thiofulvalenes are generally flat and are already known to form many stacking compounds [1]. Of equal importance, they are known to undergo partial charge transfer to a degree similar to the iridium compounds. Thus, they may have the ability to provide charge balance without forming non-stoichiometric materials. With this in mind, we sought to compare oxidation potentials of the iridium complex with several known sulfur donors. If these oxidation potentials are closely matched, the possibility exists of co-oxidation of the two species (or equivalently, of oxidation of one followed by charge redistribution to the other).

$\mathrm{TTF}+\operatorname{Ir}(\mathrm{CO})_{2}[\mathrm{Tcbiim}]^{-1} \longrightarrow \mathrm{TTF}^{+2 / 3}+\operatorname{Ir}(\mathrm{CO})_{2}[\mathrm{Tcbiim}]^{-2 / 3}+e^{-}$

A survey of the literature for electrochemical data on thiofulvalene compounds revealed many differences in experimental conditions and in 
results between research groups $[1,3,18-23]$. To overcome these inconsistencies, cyclic voltammetric data for compounds of interest were recorded in our laboratories. Data were evaluated within a given set of experimental conditions. Following the standards recently set by IUPAC for reporting electrode potentials in non-aqueous solvents, we have used reference redox couples as well as reference electrodes in our tests [24]. In some cases, two reference redox couples were used to fix two points on the potential axis.

Typical voltammograms are shown in Fig. 3 . The cyclic voltammograms of dibenzotetrathiofulvalene (DBTTF) and tetrathiofulvalene (TTF) show two one-electron waves. Most of the compounds tested were reversible. Two exceptions were the iridium complex anion and bis(ethylenedithio)tetrathiofulvalene (BEDT-TTF) (Fig. 3 (c) and (d)). The results are collected in Table 3. Despite inconsistencies in potential values relative to a given reference electrode due to unknown liquid junction potentials in nonaqueous solvents, the potentials relative to the redox couples are reliable [25].

From these data, we expect TTF to oxidize at a lower potential than the iridium complex. Indeed, in bulk electrochemical oxidations of TTF in the presence of the iridium compound, only the TTF is oxidized [26]. In the case of DBTTF, on the other hand, the iridium compound oxidizes before the sulfur donor. We are now studying donors with potentials between these values.

In order to understand further the oxidation process in the iridium complex, and to elucidate other electronic factors controlling its arrangement in the solid state, semi-empirical extended Hückel molecular orbital calculations were done on the compound. The orbitals of the anion alone (3) were calculated. Then a dimer model consisting of two stacked anions was studied to see how the energies and the metal-metal overlaps vary as a function of rotation of the molecular planes with respect to each other (Fig. 4).

Figure 5 shows part of the resulting correlation diagram of the monomer to the dimer for the most symmetric dimer arrangement with the rings eclipsing each other or a rotation angle equal to zero. In the HOMO-LUMO region, several observations can be made. Although there is little energy separation in the $d_{z^{2}}$ orbital and the ring $\pi$ orbitals in the anion complex alone, upon approach of the two anion planes during dimer formation a strong interaction develops between the metal $\mathrm{d}_{z^{2}}$ orbitals as expected for a d ${ }^{8}$ square planar transition metal species.

As a result of this interaction, the $d_{z^{2}}{ }^{*}$ orbital is pushed above the ring $\pi$-orbitals and becomes the HOMO orbital. As oxidation occurs, we expect the electrons to be removed from this metal-metal antibonding orbital, increasing the metal-metal overlap and strengthening the metal-metal bond [27]. In the limit of oxidation to Ir(II), a full metal-metal $\sigma$ bond forms $[29]$. 


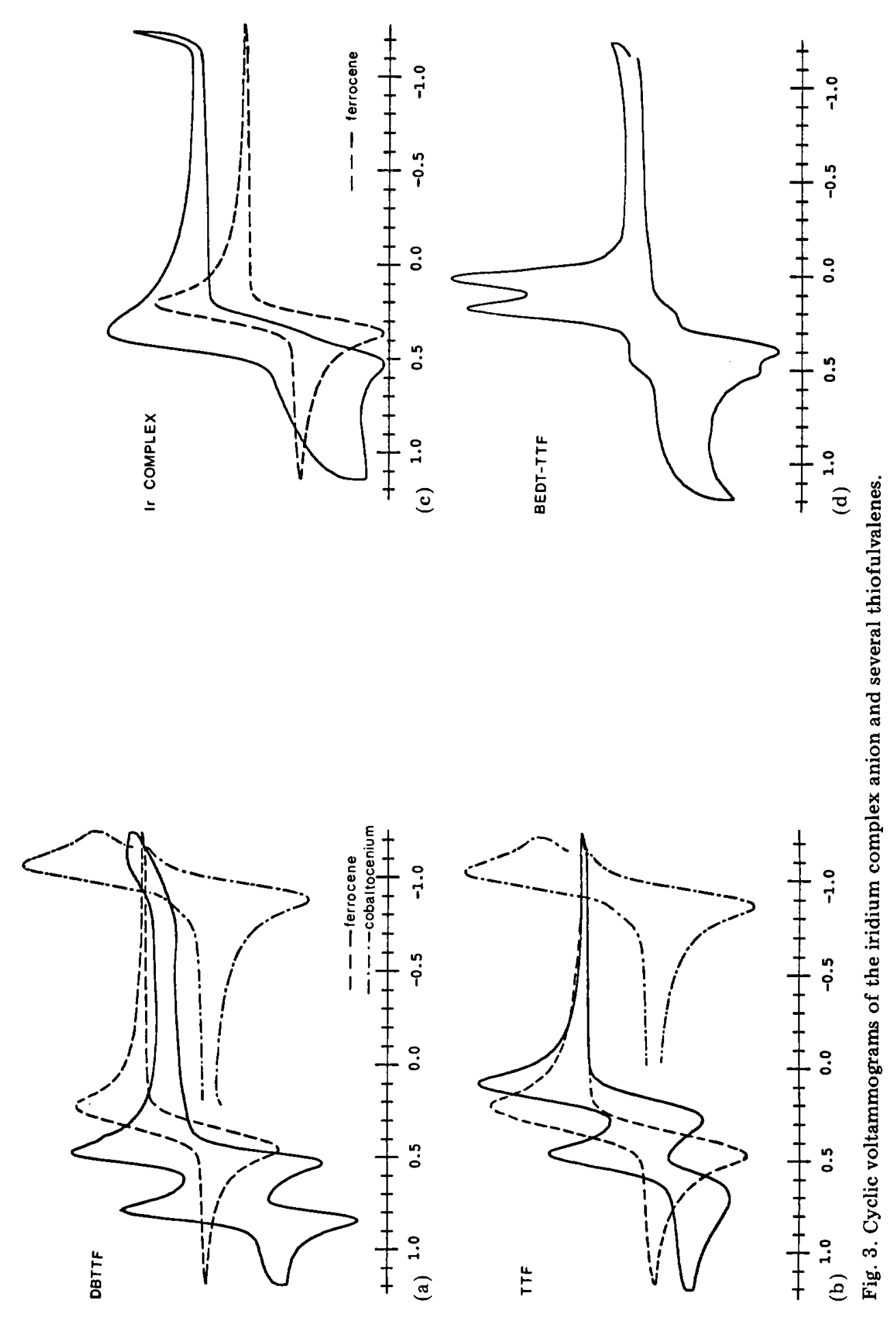




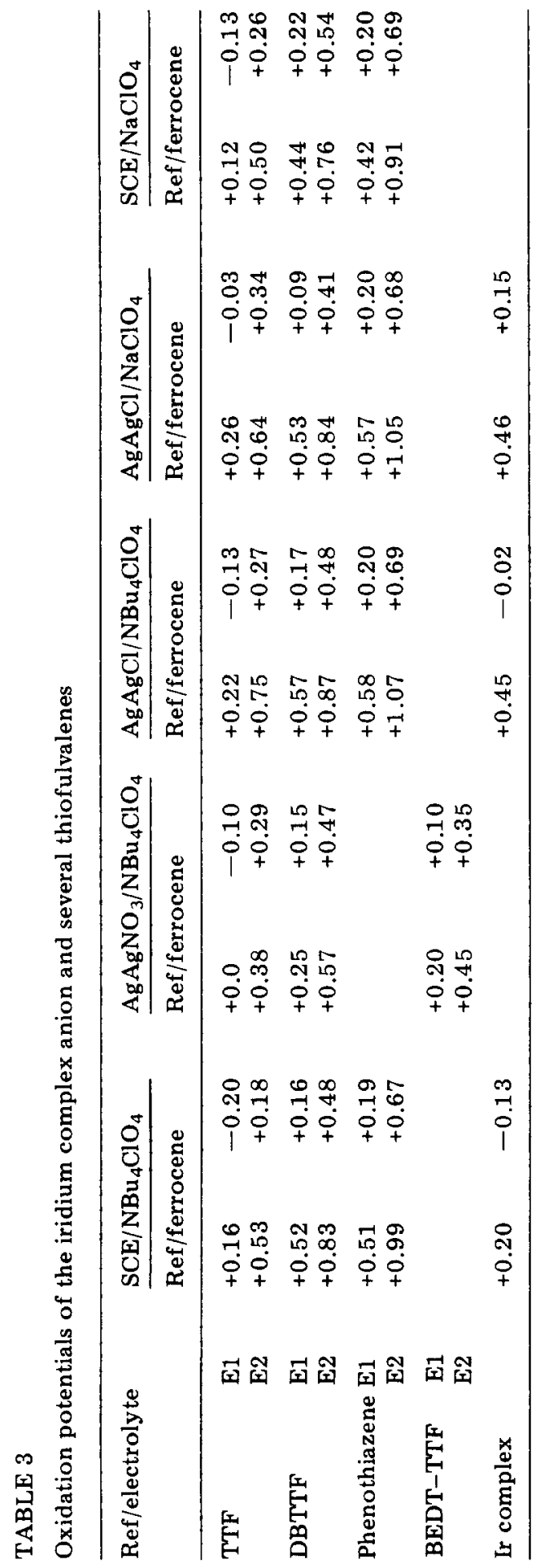




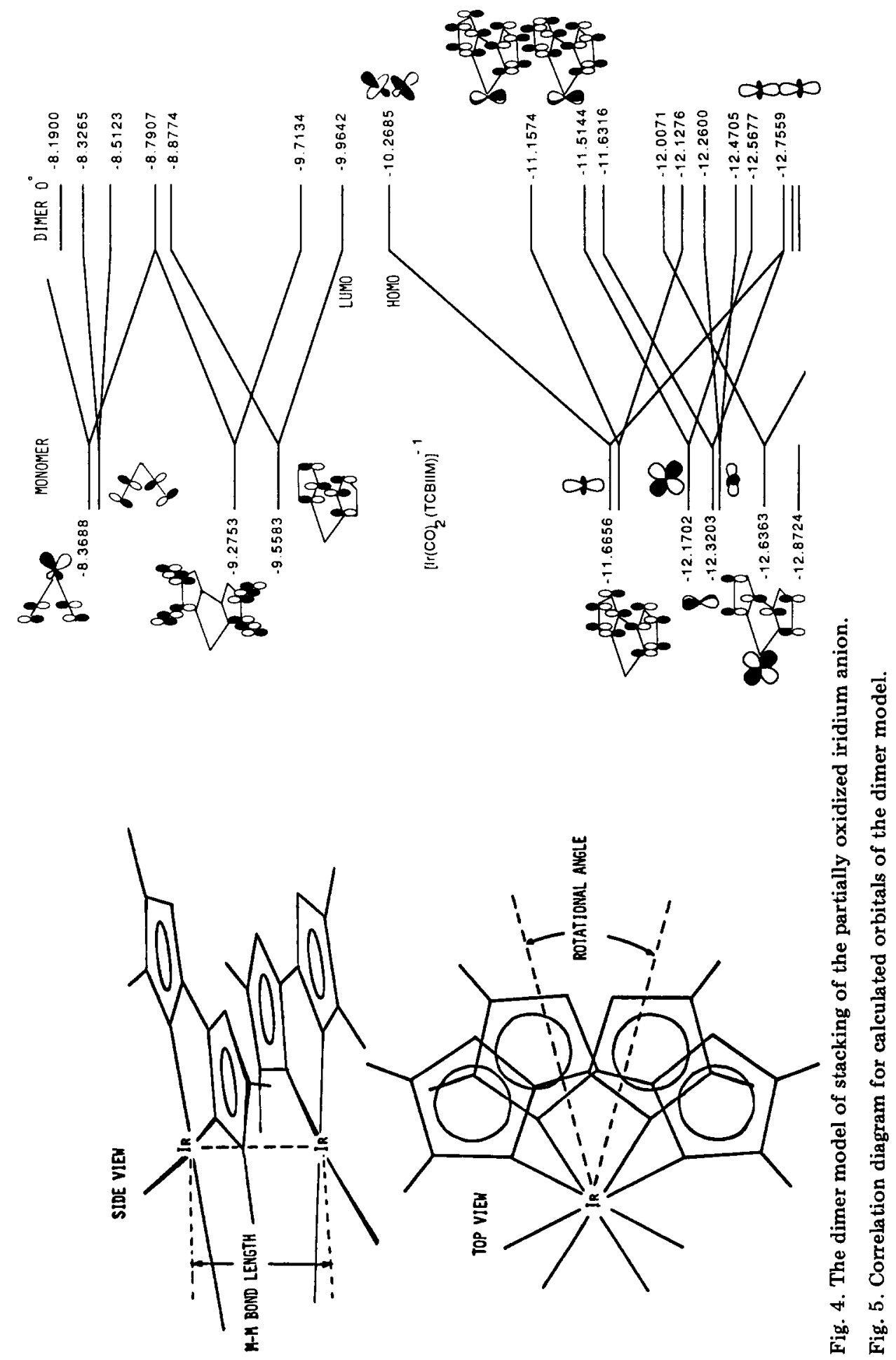


Another interesting aspect of this diagram is the interaction of the cyanoimidazole ring $\pi$ orbitals through space, forming bonding and antibonding sets of orbitals. This interaction suggests that these ligands are partially controlling the rotational angle around the metal-metal axis. As Fig. 6 (a) shows, the total energy of the dimer drops as the ligand $\pi$ systems are rotated out of each other's way, with an energy minimum occurring near the $180^{\circ}$ staggered conformation. The metal-metal overlap reaches a maximum at $180^{\circ}$ also, indicating a preference for this orientation by the
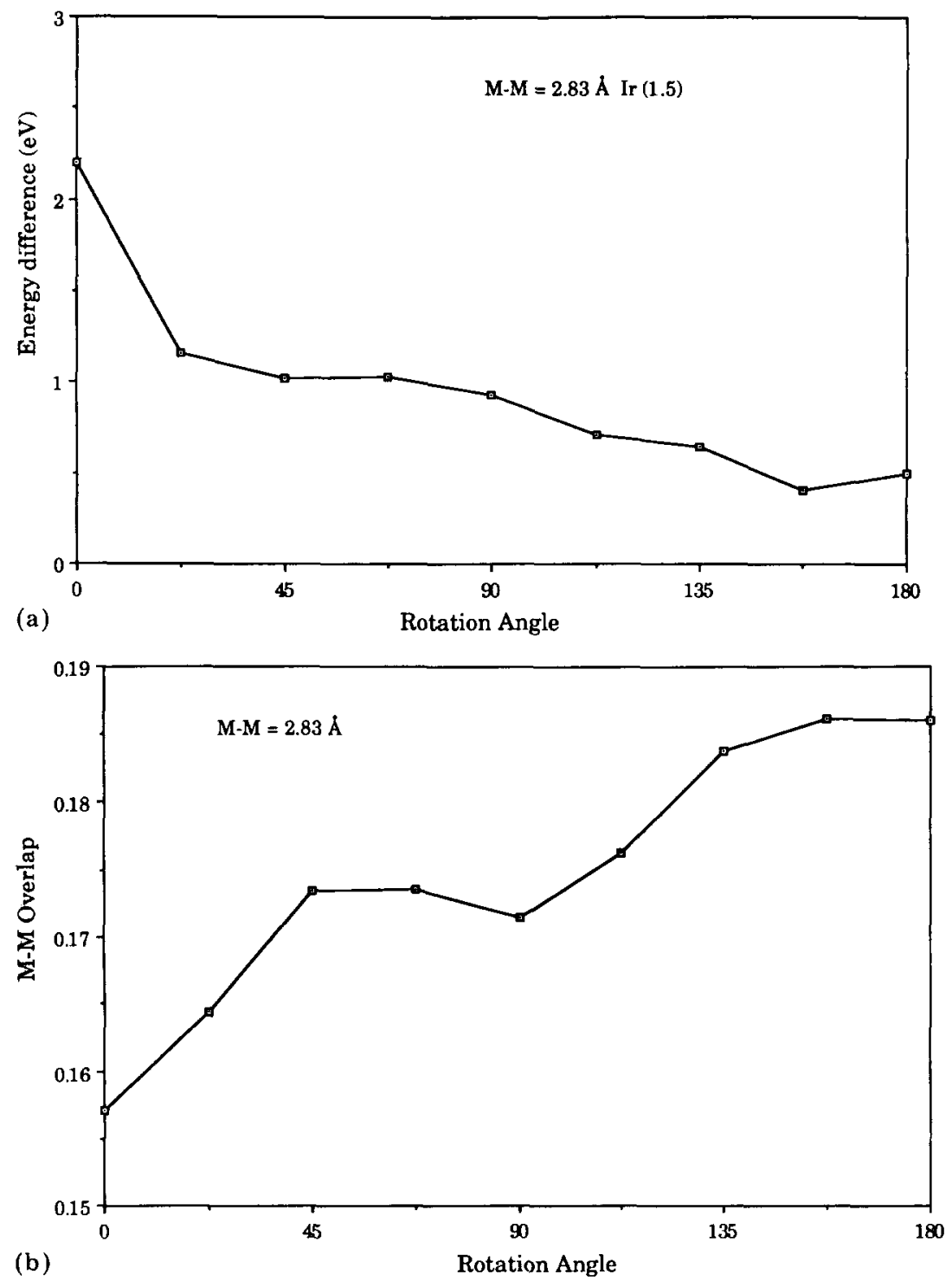

Fig. 6. Energy and $M-M$ overlap vs. rotation angle. 
metal orbitals as well (Fig. 6(b)). This is the geometry observed in the oxidized material for which structural data have been obtained [15].

\section{Conclusions}

Cyanoimidazoles form a family of moderate electron acceptors. The parent compounds, 4,5-dicyano-1-methylimidazole and 4,4',5,5'-tetracyano$1,1^{\prime}$-dimethyl-2,2'-biimidazole, were derivatized to study the effect of substitutions on the electronic properties of these compounds. The results of these structural changes were assessed by cyclic voltammetry and extended Hückel molecular orbital caculations. The experimentally determined reduction potentials correlated fairly well with the calculated LUMO energies. Both properties are related to the ability of a material to accept electrons. The correlation will allow a rough estimate to be made of reduction potentials of unsynthesized members of this family from molecular orbital calculations.

Electron acceptors can also be prepared from cyanoimidazoles by using them as stabilizing ligands for low-valent transition metal complexes. Again using cyclic voltammetry, the properties were evaluated relative to a family of known donors. In this case the sulfur donors that were examined are also candidates for countercations in the formation of stacking chargetransfer complexes with the transition metal complexes. Extended Hückel molecular orbital calculations provide a clearer electronic picture of the oxidation process and the probable structure of the transition metal complex during dimerization, the first step in formation of an extended linear solid. As more metal complexes of these cyanoimidazoles are prepared, their electrochemical properties can be evaluated similarly.

\section{Experimental}

\section{Cyclic voltammetry}

The data were obtained using a Princeton Applied Research model 173 potentiostat and a Hewlett Packard $7005 \mathrm{~b} X-Y$ recorder with a threeelectrode system. The working electrode was a $1 \mathrm{~mm}$ platinum wire or a glassy carbon electrode [28]; a platinum foil acted as the counter electrode. The reference electrode was separated from the sample compartment by a buffer compartment containing electrolyte solution and two fritted glass bridges. The internal resistance of the cell was uncompensated. All data were collected at ambient temperature. The scan rate was $100 \mathrm{mV} / \mathrm{s}$. The electrodes and cell were cleaned by soaking in concentrated nitric acid, then rinsed with water followed by acetonitrile. The components were then dried in vacuo. The acetonitrile used was HPLC grade, distilled immediately prior to use from calcium hydride, or reagent-grade solvent distilled from calcium hydride, then from phosphorus pentoxide, and finally again from calcium 
hydride just prior to use. Electrolytes were recrystallized at least three times, carefully dried in vacuo and stored under nitrogen. All cell manipulations were done under inert atmosphere using Schlenk techniques.

All cyclic voltammograms were done in acetonitrile solutions with $\mathrm{Ag} / \mathrm{AgNO}_{3}$, saturated calomel or $\mathrm{Ag} / \mathrm{AgCl}$ reference electrodes and $0.1 \mathrm{M}$ tetraethylammonium tetrafluoroborate or tetrabutylammonium perchlorate solutions as the supporting electrolyte. The cyclic voltammograms of ferrocene and cobaltocenium hexafluorophosphate were measured under the same experimental conditions and used as internal standards. Between samples, the cell was rinsed repeatedly until negligible background current was observed. The potentials used in this study were one half the sum of the peak anodic and peak cathodic potentials in the case of reversible waves. Where there is no return wave, the value reported is the potential of the peak at half height. The reported potentials are averages of several determinations in many cases.

\section{Calculations}

Extended Hückel calculations were done with the program ICON8 with the weighted $H_{i j}$ function [29]. The source file was redimensioned to accommodate the Ir dimer model compound. Parameters used in the program are shown in Table 4 [30]. Iridium $H_{i i}$ and zeta values for the $6 \mathrm{~s}$ and $6 \mathrm{p}$ orbitals are relativistic extended Hückel values, as are the $5 \mathrm{~d}$ double zetas and coefficients $[31,32]$. The value used for the $5 \mathrm{~d} H_{i i}$ is not relativistic [33]. Bond lengths and angles in the iridium complexes were idealized slightly to maintain $C_{2 v}$ symmetry.

TABLE 4

Parameters used in ICON8 calculations

\begin{tabular}{lll}
\hline Orbital & $H_{i i}(\mathrm{eV})$ & Zeta \\
\hline H 1s & -13.60 & 1.300 \\
C 2s & -21.40 & 1.625 \\
C 2p & -11.40 & 1.625 \\
N 2s & -26.00 & 1.950 \\
N 2p & -13.40 & 1.950 \\
O 2s & -32.30 & 2.275 \\
O 2p & -14.80 & 2.275 \\
\hline
\end{tabular}

\begin{tabular}{llllll}
\hline Orbital & $H_{i i}(\mathrm{eV})$ & Zeta 1 & Zeta 2 & C1 & C2 \\
\hline Ir 6s & -8.20 & 2.11 & & & \\
Ir 6p & -4.17 & 1.69 & & & \\
Ir 5d & -12.17 & 3.974 & 1.828 & 0.781 & 0.367 \\
\hline
\end{tabular}




\section{Materials}

$\mathrm{Na}\left[\operatorname{Ir}(\mathrm{CO})_{2}(\mathrm{Tcbiim})\right]$ (3) was synthesized by methods previously reported [34]. Tetrathiofulvalene (TTF), phenothiazene and ferrocene were obtained commercially and sublimed prior to use. Cobaltocenium hexafluorophosphate was purchased from Aldrich and used without further purification. Dibenzotetrathiofulvalene (DBTTF) was donated by Torrance [35] and bis(ethylenedithio)tetrathiofulvalene (BEDT-TTF) was given to us by Williams [36].

4,5-Dicyanoimidazole, 4,5-dicyano-1-vinylimidazole and 4,4',5,5'-tetracyano-2,2'-biimidazole were synthesized as reported previously [37-39].

Infrared spectra were recorded on a Nicolet 5DX FTIR spectrometer. Proton and carbon-13 nuclear magnetic resonance spectra were recorded on a Bruker AM-300 n.m.r. spectrometer. Nominal mass spectra were done on a Finnigan model 4021 quadrupole mass spectrometer; high-resolution mass spectra were recorded on a VG Analytical model 70-250S mass spectrometer. Elemental analyses were performed by Galbraith Analytical Laboratories, Knoxville, TN.

\section{4,5-Dicyano-1-methylimidazole}

Into a 25-ml three-neck roundbottom flask equipped with a condenser, heating mantle, magnetic stirrer and nitrogen atmosphere were placed $3 \mathrm{~g}$ $(25.4 \mathrm{mmol})$ of 4,5 -dicyanoimidazole and $15 \mathrm{ml}$ of freshly distilled 1,2 dimethoxyethane. Triethylamine $(3.6 \mathrm{ml}, 25.4 \mathrm{mmol})$ was added and the solution was stirred for $15 \mathrm{~min}$. Iodomethane $(3.43 \mathrm{ml}, 55.1 \mathrm{mmol})$ was added slowly and the mixture was stirred for $12 \mathrm{~h}$. The triethylamine hydroiodide salt precipitated from the solution $15 \mathrm{~min}$ after addition of the iodomethane. The salt was filtered from the solution and the solvent removed from the filtrate. The resulting solid was dissolved in chloroform and washed with dilute ammonium hydroxide solution and water. The organic layer was dried over $\mathrm{MgSO}_{4}$ and the solvent was removed to yield $2.02 \mathrm{~g}$ of product $(60 \%)$. The product was crystallized from $95 \%$ ethanol. Melting point, $90-91{ }^{\circ} \mathrm{C}$. Infrared $(\mathrm{KBr}) 3139,3126,2237,1528,1506$, $1465,1421,1362,1317,1246,1180,1032,860,751,633,505 \mathrm{~cm}^{-1}$. ${ }^{1} \mathrm{H}$ n.m.r. $\left(\mathrm{CDCl}_{3}\right) 7.671 \mathrm{H} \mathrm{s}, 3.903 \mathrm{H}$ s. HRMS, calcd. for $\mathrm{C}_{6} \mathrm{H}_{4} \mathrm{~N}_{4}$, 132.0436; found, 132.0437 .

\section{$4,4^{\prime}, 5,5^{\prime}$-Tetracyano-1,1'-dimethyl-2,2'-biimidazole}

To a flask containing $0.109 \mathrm{~g}(0.29 \mathrm{mmol})$ of $4,4^{\prime}, 5,5^{\prime}$-tetracyano2,2 '-biimidazole bis(tetramethylammonium) salt in $10 \mathrm{ml}$ of dry acetonitrile was added iodomethane $(4.5 \mathrm{~g}, 32 \mathrm{mmol})$. The mixture was stirred for $18 \mathrm{~h}$. The remaining iodomethane was removed under reduced pressure, and the precipitated tetramethylammonium iodide salt was removed by filtration through a medium glass frit. The solvent volume was further reduced to yield a white solid, which was purified by crystallization to yield $0.050 \mathrm{~g}$ of the desired product $(66 \%)$. Melting point $218-221{ }^{\circ} \mathrm{C}$. Infrared $(\mathrm{KBr}) 3013$, $2241,1484,1455,1403,1357,950,945 \mathrm{~cm}^{-1}$. MS $(m / e) 262\left(\mathrm{M}^{+}\right), 261$, 
158, 132, 77, 67, 52. HRMS, calcd. for $\mathrm{C}_{12} \mathrm{H}_{6} \mathrm{~N}_{8}, 262.0715$; found, 262.0704 .

Tetraethylammonium salt of 2,4,5-tricyanoimidazole

(This procedure follows that in [40]). To a mixture of $1.44 \mathrm{~g}(10.8$ $\mathrm{mmol}$ ) of 2-amino-4,5-dicyanoimidazole [41] in $30 \mathrm{ml}$ of water were added $12 \mathrm{ml}$ of concentrated $\mathrm{HCl}$ and $0.84 \mathrm{~g}(12.2 \mathrm{mmol})$ of $\mathrm{NaNO}_{2}$. The 2-diazo4,5-dicyanoimidazole zwitterion precipitated and was isolated by filtration. CAUTION: the diazonium zwitterion is extremely shock- and heat-sensitive. It should be prepared in small quantities only and handled while moist. The zwitterion was added to a solution of $1.11 \mathrm{~g}(22.7 \mathrm{mmol})$ of $\mathrm{NaCN}$ and $1.30 \mathrm{~g}$ (14.5 mmol) of CuCN in $100 \mathrm{ml}$ of water. Nitrogen gas evolved immediately. The reaction was stirred for $3 \mathrm{~h}$, at which time $8.41 \mathrm{~g}(40 \mathrm{mmol})$ of tetraethylammonium bromide were added. The dark reaction mixture was filtered and then extracted with dichloromethane $(10 \times 50 \mathrm{ml})$. The organic extracts were combined and the solvent was evaporated to give $1.63 \mathrm{~g}$ of the tetraethylammonium salt $(58 \%)$. The salt was recrystallized from water to give a yellow-orange solid. Melting point $95-96{ }^{\circ} \mathrm{C}$. Infrared $(\mathrm{KBr}) 3014$, 2957, 2226, 2200, 1487, 1390, 1175, 1144, 997, $786 \mathrm{~cm}^{-1}$. ${ }^{1} \mathrm{H}$ n.m.r. $\left(\mathrm{CDCl}_{3}\right) 3.33(\mathrm{q} 8 \mathrm{H} J=7.3 \mathrm{~Hz}), 1.39\left(\mathrm{tt} 12 \mathrm{H} J_{\mathrm{H}-\mathrm{H}}=7.3 \mathrm{~Hz}, J_{\mathrm{H}-\mathrm{N}}=1.8 \mathrm{~Hz}\right)$.

\section{2,4,5-Tricyano-1-methylimidazole}

To a solution of $0.265 \mathrm{~g}(1.02 \mathrm{mmol})$ of the tetraethylammonium salt in $15 \mathrm{ml}$ of freshly distilled THF was added $0.1 \mathrm{ml}(1.0 \mathrm{mmol})$ of dimethylsulfate. The mixture was stirred overnight at $25{ }^{\circ} \mathrm{C}$. A precipitate formed and was removed by filtration. The solvent was removed from the filtrate and the viscous oil that remained was taken up in dichloromethane, washed with aqueous ammonia and finally washed with water. The organic layer was dried over $\mathrm{Na}_{2} \mathrm{SO}_{4}$, filtered and stripped of solvent to give a tan solid. The solid was purified by sublimation at $85{ }^{\circ} \mathrm{C}$ and 0.8 Torr to give $0.065 \mathrm{~g}$ of white solid (40\%). Melting point $115-116{ }^{\circ} \mathrm{C}$. Infrared $(\mathrm{KBr}) 2966$, 2924, 2246, $1476 \mathrm{~cm}^{-1} .{ }^{1} \mathrm{H}$ n.m.r. $\left(\mathrm{CDCl}_{3}\right) 4.05$ s. ${ }^{13} \mathrm{C}$ n.m.r. $\left(\mathrm{CDCl}_{3}\right) 126.5$, $122.9,115.8,110.3,107.9,106.6,35.0$. MS $(m / e) 157\left(\mathrm{M}^{+}\right), 156,116$, 105, 67. HRMS, calcd. for $\mathrm{C}_{7} \mathrm{H}_{3} \mathrm{~N}_{5}, 157.0388$; found, 157.0390.

\section{2-Bromo-4,5-dicyanoimidazole}

$10 \mathrm{ml}(29.3 \mathrm{~g}, 183 \mathrm{mmol})$ of $\mathrm{Br}_{2}$ was added slowly to a solution of $5.00 \mathrm{~g}$ (42.4 mmol) of 4,5-dicyanoimidazole in $100 \mathrm{ml}$ of $0.1 \mathrm{M}$ sodium hydroxide solution. The flask was loosely stoppered with a tuft of glass wool and the mixture was stirred for $18 \mathrm{~h}$. The glass wool was removed and the flask was stirred until the excess bromine had escaped from the flask. The precipitated product was isolated by filtration and then purified by recrystallization from water to yield $7.53 \mathrm{~g}(90 \%)$. Melting point 148 $149{ }^{\circ} \mathrm{C}$. Infrared (KBr) 3491, 3221, 3068, 2993, 2911, 2856, 2781, 2697, $2653,2466,2248,1496,1481,1407,1364,1289,997,965,507 \mathrm{~cm}^{-1}$. MS $(m / e) 196,198(\mathrm{M}, \mathrm{M}+2), 169,171,91,64,53,38 .{ }^{1} \mathrm{H}$ n.m.r. $\left(\mathrm{CDCl}_{3}\right)$ 
11.2 s. ${ }^{13} \mathrm{C}$ n.m.r. (acetone-d ${ }_{6}$ ) 132.3, 120.8, 116.1. Anal. obs. C 30.44 , H 0.66, N 28.33, calc. C 30.49, H 0.51, N 28.44.

\section{2-Bromo-4,5-dicyano-1-methylimidazole}

To a solution of $2.50 \mathrm{~g}(12.7 \mathrm{mmol})$ of 2-bromo-4,5-dicyanoimidazole in $12 \mathrm{ml}$ of freshly distilled THF was added $1.8 \mathrm{ml}(12.7 \mathrm{mmol})$ of triethylamine. The solution was stirred for $30 \mathrm{~min}$ and then $1.20 \mathrm{ml}(12.7 \mathrm{mmol})$ of dimethylsulfate was added. The reaction was stirred at room temperature for two days. An oil that formed at the bottom of the flask was removed by pipet. The solvent was then evaporated. The residual solid was taken up in dichloromethane and washed with aqueous ammonia and saturated sodium chloride solution. The organic layer was dried over $\mathrm{Na}_{2} \mathrm{SO}_{4}$ and then evaporated to give a yellow-white solid. The solid was recrystallized from $95 \%$ ethanol to give $2.16 \mathrm{~g}$ of product $(81 \%)$. Melting point $135-136{ }^{\circ} \mathrm{C}$. Infrared (KBr) 2924, 2241, 1468, 1373, $1311 \mathrm{~cm}^{-1} .{ }^{1} \mathrm{H}$ n.m.r. $\left(\mathrm{CDCl}_{3}\right) 3.89 \mathrm{~s}$. ${ }^{13} \mathrm{C}$ n.m.r. $\left(\mathrm{CDCl}_{3}\right) 126.8,122.9,115.1,110.6,107.3,35.1 . \mathrm{MS}(\mathrm{m} / \mathrm{e})$ $210,212(\mathrm{M}, \mathrm{M}+2), 131,79,67$. HRMS, calcd. for $\mathrm{C}_{6} \mathrm{H}_{3} \mathrm{BrN}_{4}, 209.9541$; found, 209.9543 .

\section{Acknowledgements}

We are grateful to the following people for supplying samples of their compounds for this study: P. G. Apen, J. B. Torrance and J. M. Williams.

P. G. Rasmussen acknowledges support from the donors of the Petroleum Research Foundation administered by the American Chemical Society. D. S. Allan acknowledges support from the National Science Foundation and the Macromolecular Research Center of the University of Michigan.

\section{References}

1 R. C. Wheland and J. L. Gillson, J. Am. Chem. Soc., 98 (1976) 3916 - 3925.

2 G. Saito and J. P. Ferraris, Bull. Chem. Soc. Jpn., 53 (1980) $2141-2145$.

3 J. B. Torrance, Accounts Chem. Res., 12 (3) (1979) $79-86$.

4 R. C. Wheland, J. Am. Chem. Soc., 98 (1976) $3926-3930$.

5 Z. G. Soos, H. J. Keller, W. Moroni and D. Noethe, Ann. N.Y. Acad. Science, (1978) 442 .

6 A. F. Garito and A. J. Heeger, Accounts Chem. Res., 7 (1974) 232.

7 J. B. Torrance, Mol. Cryst. Liq. Cryst., 126 (1) (1985) 55 - 67.

8 J. E. Anderson, Ph.D. Thesis, University of Michigan, 1985.

9 Unpublished work.

10 M. R. Grimmett, in A. R. Katritzky and A. J. Boulton (eds.), Advances in Heterocyclic Chemistry, Vol. 12, Academic, New York, 1970, p. 103.

11 P. G. Rasmussen, O. H. Bailey and J. C. Bayón, Inorg. Chem., 23 (1984) 338 - 343.

12 P. G. Rasmussen, J. E. Anderson, O. H. Bailey and M. Tamres, J. Am. Chem. Soc., 107 (1985) $279-281$. 
13 P. H. Rieger, I. Bernal, W. H. Reinmuth and G. K. Fraenkel, J. Am. Chem. Soc., 85 (1963) 683-693.

14 P. H. Rieger and G. K. Fraenkel, J. Chem. Phys., 37 (1962) $2795-2810$.

15 J. E. Mulvaney, R. J. Cramer and H. K. Hall Jr., J. Polym. Sci. Polym. Chem. Ed., 21 (1983) $309-314$.

16 J. B. Kolowich, Ph.D. Thesis, University of Michigan, 1987.

17 P. G. Rasmussen, J. B. Kolowich and J. C. Bayón, J. Am. Chem. Soc., in press.

18 M. Bousseau, Ph.D. Thesis, L'Université Paul Sabatier de Toulouse, 1984.

19 D. L. Coffen, J. Q. Chambers, D. R. Williams, P. E. Garrett and N. D. Canfield, J. Am. Chem. Soc., 93 (1971) 2258 - 2268.

20 M. Mizuno, A. F. Garito and M. P. Cava, J. Chem. Soc. Chem. Commun., (1978) 18.

21 F. B. Kaufman, E. M. Engler and D. C. Green, J. Am. Chem. Soc., 98 (1976) 1596 1597.

22 E. M. Engler, F. B. Kaufman and D. C. Green, J. Am. Chem. Soc., 97 (1975) 2921 2922.

23 K. Bechgaard, D. O. Cowan and A. N. Bloch, Mol. Cryst. Liq. Cryst., 32 (1 - 4) (1976) $227-230$.

24 G. Gritzner and J. Kuta, J. Pure Appl. Chem., 56 (4) (1984) 461 - 466.

25 H. M. Koepp, H. Wendt and H. Strehlow, Z. Electrochem., 64 (1960) $483-491$.

26 Unpublished work.

27 J. S. Miller and A. J. Epstein, Prog. Inorg. Chem., 20 (1976) 1 - 151.

28 R. Moy, Analyst, 111 (1986) $883-885$.

29 J. H. Ammeter, H.-B. Buergi, J. C. Thibeault and R. Hoffmann, J. Am. Chem. Soc., $100(12)(1978) 3686-3692$.

30 R. Hoffmann, J. Chem. Phys., 39 (1963) 1397.

31 Lawrence L. Lohr, University of Michigan, Ann Arbor, MI, personal communication.

32 N. J. Fitzpatrick and G. H. Murphy, Inorg. Chim. Acta, 111 (1986) $139-140$.

33 H. Basch and H. B. Gray, Theor. Chim. Acta, 4 (1966) $367-376$.

34 O. H. Bailey, Ph.D. Thesis, University of Michigan, 1983.

35 J. B. Torrance, IBM Research Center, San Jose, CA.

36 J. M. Williams, Argonne National Laboratories, Argonne, IL.

37 R. W. Begland, D. R. Hartter, F. N. Jones, D. J. Sam, W. A. Sheppard, O. W. Webster and F. J. Weigert, J. Org. Chem., 39 (1974) 2341 - 2350.

38 P. G. Rasmussen, R. L. Hough, J. E. Anderson, O. H. Bailey and J. C. Bayón, J. Am. Chem. Soc., 104 (1982) 6155-6156.

39 Y. Yamada, I. Kumashiro and T. Takenishi, Bull. Chem. Soc., Jpn., 41 (1968) 1237 1240.

40 O. W. Webster, U.S. Patent 3882140 (1975); Chem. Abstr., 80:1426v.

41 W. A. Sheppard and O. W. Webster, J. Am. Chem. Soc., 95 (1973) 2695 - 2697. 